\title{
HUME CRÍTICO DE LOCKE: CONTRATO SOCIAL E WHIGGISM
}

\author{
Eveline Hauck* \\ evelinehauck@hotmail.com
}

RESUMO $A$ crítica de Hume ao contrato social admite um alcance para além do debate com o contratualismo de Locke: nosso autor tem em vista, sobretudo, desconstruir os princípios filosóficos que são a base da prática política dos Whigs. Uma vez que o contrato original organiza esses princípios, Hume se dedicará a analisá-lo em termos filosóficos e históricos, na tentativa de modernizar o pensamento político de sua época.

Palavras-chave: Hume, Contrato social, Locke, Whiggism.

ABSTRACT Hume's criticism of the social contract allows a range beyond the debate with Locke's theory: our author aims mainly to deconstruct the philosophical principles that are the basis of the political practice of the Whigs. Since the original contract organizes these principles, Hume will be devoted to evaluating it in philosophical and historical terms, in an attempt to modernize the political thought of his time.

Keywords: Hume, Social contract, Locke, Whiggism.

É bem conhecida a crítica de Hume à teoria do contrato social tal como exposta no "Tratado da natureza humana": ainda que na história particular de algumas nações tenha havido no início da sociedade algum tipo de contrato, tácito

* USP. Artigo submetido em 23/06/2016 e aprovado em 13/09/2016.

KRITERION, Belo Horizonte, n 136 , Abr./2017, p. 87-100 
ou expresso, a fim de garantir a ordem e a paz entre os indivíduos estabelecendo um governo, o consentimento que ele implica não é a fonte da legitimidade política. No entanto, julgamos importante elucidar o alcance que essa crítica adquire em alguns ensaios, principalmente em "Do contrato original" ("Ensaios Morais, Políticos e Filosóficos"); Hume analisa a teoria do contrato social a fim de desconstruir os princípios filosóficos e históricos que são a base da prática política dos Whigs. Muito embora possamos encontrar nos "Ensaios" uma crítica aos Tories, Hume discute, sobretudo, os princípios dos teóricos Whigs, em especial de Locke - "o partidário mais notável” (Hume, 1994, p. 486) -, justamente por ser este o partido com mais poder no período em que escreve. Locke não é o único, nem o maior, teórico Whig, mas com frequência Hume endereça sua crítica a ele para avaliar genericamente os princípios de seus partidários. ${ }^{1}$

Nossa intenção é analisar, de modo preliminar, a crítica de Hume ao contrato social, tal como explicitada no "Tratado", para posteriormente localizar em sua política, desenvolvida nos "Ensaios", a importância da discussão sobre os partidos políticos em geral e particularmente na Inglaterra. É relevante apontar que a teoria Whig será compreendida tal como apresentada por Hume em seus textos, a despeito de sua complexidade e das controvérsias entre seus teóricos.

Primeiramente, o estabelecimento do governo ou da sociedade política é um passo ulterior à formação da sociedade. Esta não é mais que uma convenção ou acordo que institui, ainda que de modo gradual, leis de justiça, que são "aquelas três leis fundamentais concernentes à estabilidade da posse, à sua transferência por consentimento e ao cumprimento de promessas" (Hume, 2009, p. 580). Segundo Hume, a sociedade é "apenas um sentido geral de interesse comum, que todos os membros da sociedade expressam mutuamente, e que os leva a regular sua conduta segundo certas regras" (Hume, 2009, p. 530). Os membros dessa sociedade, motivados por um interesse comum, veem como vantajosa a abstenção da posse alheia, pois só assim poderão usufruir em paz de sua propriedade e dos frutos de seu trabalho. É possível, e a experiência nos prova, que algumas sociedades sobrevivam por muito tempo sem governo, principalmente quando "os bens e os prazeres da vida são poucos e de pouco valor" (Hume, 2009, p. 578). No momento do estabelecimento da sociedade, não há ainda uma obrigação para o cumprimento de promessas, ${ }^{2}$ pois as leis de

1 A controversa relação de Locke com o Whiggism é analisada em Rudolph (2002).

2 "Essa convenção não tem a natureza de uma promessa, pois mesmo as promessas, como veremos posteriormente, dependem das convenções humanas” (Hume, 2009, p. 530). 
justiça são tão artificiais quanto a própria sociedade humana, e têm o mesmo propósito de garantir a paz e a segurança dos indivíduos.

Poderíamos concluir, então, que uma vez que as leis de justiça passaram a ser observadas, quando os membros de uma sociedade estabelecem seu governo, a obediência que conferem aos magistrados decorre de uma promessa, um consentimento à submissão?

Esse raciocínio parece tão natural que se tornou o fundamento do sistema político hoje em voga entre nós, sendo de certa maneira o credo de um de nossos partidos, cujos membros se orgulham, com razão, da correção de sua filosofia e de sua liberdade de pensamento. Todos os homens, dizem eles, nascem livres e iguais; o governo e a superioridade só podem se estabelecer pelo consentimento; o consentimento dos homens, quando estabelecem o governo, impõe-lhes uma nova obrigação, desconhecida do direito natural. Os homens, portanto, só são obrigados a obedecer a seus magistrados porque assim o prometeram; se não tivessem, expressa ou tacitamente, dado sua palavra de manter a obediência, esta nunca se teria tornado parte de seu dever moral. (Hume, 2009, p. 581, grifos do original)

Esse "sistema político hoje em voga" é o sistema dos Whigs cujo princípio filosófico é o contrato social. Os trechos citados, sem qualquer menção ao autor, podem ser identificados com passagens do "Segundo Tratado sobre o Governo" de Locke. ${ }^{3}$ Nesse momento, a crítica de Hume a Locke recai principalmente na noção de que a obediência civil tem como fundamento, "em todas as épocas e situações", uma promessa, o que pressupõe considerar "a justiça uma virtude natural e anterior às convenções humanas” (Hume, 2009, p. 581). Afirmar que os indivíduos em seu estado de natureza foram capazes de acordar entre si um contrato para fundar a sociedade por meio de uma promessa significa imiscuir a natureza humana de uma capacidade que é desenvolvida apenas por convenção humana. ${ }^{4}$ Segundo Forbes $(1975$, p. 67),

a teoria do contrato que Hume atacou dependia de alguma sanção sobrenatural; para os contratualistas, a promessa, diferentemente do governo, não era apenas mais uma invenção a partir dos interesses da sociedade, ou seja, a sociedade humana no sentido mais 'vulgar' e 'limitado', que é, para Hume, seu único significado.

3 Mais propriamente com passagens do capítulo VIII, Do Começo das Sociedades Políticas. Por exemplo: "Sendo os homens, conforme acima dissemos, por natureza, todos livres, iguais e independentes, ninguém pode ser expulso de sua propriedade e submetido ao poder político de outrem sem dar consentimento" e "E assim todo homem, concordando com outros em formar um corpo político sob governo, assume a obrigação para com todos os membros dessa sociedade de submeter-se à resolução da maioria conforme a assentar [...]" (Locke, 1983, p. 71).

4 Hume admite dois tipos de virtudes, as naturais e as artificiais. As virtudes artificiais "produzem prazer e aprovação mediante um artifício ou invenção resultante das particularidades e necessidades da humanidade" (Hume, 2009, p. 517); essas são a justiça (no que diz respeito à propriedade), a fidelidade a promessas, a obediência ao governo, entre outras. 
O homem natural de Locke é regido pela lei de natureza, que nada mais é que o uso de sua razão, assegurada por deus, para fins de sua própria preservação (preservação de sua propriedade que abrange, além do fruto de seu trabalho, também a sua vida) e para a preservação de toda a humanidade; e sendo livre, igual e independente de qualquer outro homem, ele só se submete ao poder político por um ato de sua vontade, por consentimento. Esse consentimento transfere o poder de cada indivíduo de executar a lei de natureza para outrem, o que garante a submissão dos membros de uma comunidade ao corpo político: o que quer dizer que o consentimento para formação da sociedade, em Locke, é também um consentimento de submissão, tanto nos primórdios das nações quanto em qualquer outro momento da história, mesmo que a sociedade já esteja constituída, pois ainda ali todos os indivíduos nascem livres.

Para Hume, a formação da sociedade política, embora passível de muitas facticidades, pode ser também delimitada por princípios gerais que são garantidos pela uniformidade da natureza humana. Quais aspectos da natureza humana fazem o governo necessário, ainda que evitável? A essa pergunta, Hume responderá de forma negativa: efetivamente, não é uma qualidade da natureza humana que conduz os indivíduos a se estabelecerem em uma sociedade política, mas carências, ou seja, são os traços humanos negativos que tornam o governo vantajoso, e não uma série de características positivas. Portanto, Hume não atribui o estabelecimento do governo à justiça ou sociabilidade naturais do homem - ainda que conceba virtudes naturais -, pois seu alcance é restrito, bem como é restrito o seu interesse próprio. ${ }^{5}$ Se o interesse na manutenção da propriedade uniu os indivíduos em sociedade, um outro interesse, resultado de uma fraqueza da natureza humana, uni-los-á em uma sociedade política: como os seres humanos tendem a agir em favor do que é contíguo, em prejuízo do que é remoto, será necessário um expediente que assegure a observância das leis de justiça e equidade, as quais estão, muitas vezes, em conflito com seus interesses mais imediatos:

É por essa razão que os homens, com tanta frequência, agem em contradição com seu reconhecido interesse; em particular, é por essa razão que preferem qualquer vantagem trivial, mas presente, à manutenção da ordem na sociedade, que depende em tão grande medida da observância da justiça. As consequências de cada violação da equidade parecem tão remotas, não sendo capazes de contrabalançar as vantagens imediatas que se podem extrair dessa violação (Hume, 2009, p. 574). um estado de guerra permanente, e que a única possibilidade de escape dessa situação é a instituição do governo. 
Assim, a mesma natureza que carece de uma propriedade positiva para a conservação de seu interesse oferece aos indivíduos a capacidade de inventar o seu próprio remédio, e esse remédio é a instituição de um indivíduo, ou conjunto de indivíduos, que, indiferente à maioria dos membros da sociedade, possa exercer com equidade a justiça e constranger atos de injustiça com a mesma regularidade (Hume, 2009, p. 575).

De que modo, então, esse remédio será acordado entre os indivíduos? Haverá um contrato? Um acordo expresso sobre quem e como será feita a distribuição da justiça?

No ensaio "Da origem do governo", lemos:

minha intenção aqui não é negar o consentimento popular como um fundamento justo de um eventual governo; trata-se certamente do melhor e mais sagrado fundamento. Apenas considero que ele raramente se deu de alguma forma e nunca em sua totalidade; por isso deve-se admitir ainda um outro fundamento para o governo (Hume, 1994, p. 474).

Nesse momento da argumentação, Hume rejeita um princípio universal para todos os governos, como queriam os contratualistas. Na verdade, podemos responder por que os seres humanos estabelecem governos, dada sua natureza comum, no entanto, é mais precário indicar regras gerais para explicar como o poder político surgiu em cada nação. É possível, portanto, apenas conceber algumas características gerais que fazem com que alguns indivíduos se sobressaiam a outros e adquiram mais poder ante uma sociedade, como valor, força, integridade e prudência, e também delinear uma ocasião mais propícia para que isso ocorra - "é provável que a primeira vez que um homem ganhou ascendência sobre multidões tenha sido num estado de guerra" (Hume, 2008, p. 39), mas é incorreto determinar um princípio único que dê conta da pluralidade de circunstâncias que estão na origem dos governos. Afirmar que há na natureza humana aspectos positivos ou negativos que ensejam a sociedade e o governo não é o mesmo que traçar universalmente a sua gênese, "pois a história de épocas remotas se encontra amiúde envolta em obscuridade, incerteza e contradição" (Hume, 2015, p. 1).

Por causa dessa dificuldade de se reconstruírem os fatos históricos a fim de estabelecer de forma segura uma origem é que Hume pode mesmo considerar que em algumas sociedades a formação do governo se deu por intermédio de um pacto ou contrato entre seus membros. No entanto, os contratualistas confundiram o consentimento para a formação do governo com o consentimento de obediência.

É evidente que nenhum pacto ou acordo foi expressamente firmado para a submissão geral; uma ideia muito além da compreensão dos selvagens. Cada exercício de autoridade 
do chefe deve ter sido particular e suscitado pela exigência presente do caso; a utilidade consciente, resultante de sua interposição, fez com que seus exercícios se tornassem cada dia mais frequentes, e sua frequência produziu gradualmente um hábito, e, se quiser chamá-la assim, uma aquiescência voluntária, e por isso precária, no povo (Hume, 1994, pp. 468-469).

O que Hume faz questão de reforçar é que o fundamento da obediência está na vantagem que ela traz aos homens e no hábito. $\mathrm{O}$ erro ainda mais grave de alguns contratualistas, como de Locke, é aplicar o mesmo princípio que deu origem a um governo, ou seja, o consentimento, em um período remoto à aquiescência que prestamos hoje aos governantes: ainda que porventura nossos ancestrais tenham consentido ou acordado voluntariamente nos primórdios da nação obedecer ao primeiro indivíduo que se destacou na sociedade, nossa aquiescência ao governo atual dá-se por hábito e interesse. Na verdade, a obediência civil surge com a sociedade, ou seja, é um dever constituído ao longo do tempo e apoiado em opinião.

No ensaio "Dos primeiros princípios do governo", Hume diz que há dois tipos de opinião que dão sustentação aos governantes: opinião de interesse e opinião de direito. Aquela opinião refere-se à propensão que temos a desejar o que nos é mais vantajoso, e temos o "sentido da vantagem geral que é obtida por meio do governo" (Hume, 1994, p. 33); esta pode ainda ser subdividida em dois tipos, direito ao poder e direito à propriedade. $\mathrm{O}$ longo tempo em que um governante ou família de governantes está no poder dá ensejo à noção de seu direito a ele, e isso entendemos facilmente quando "observamos a ligação que todas as nações têm com seu governo antigo e mesmo com aqueles nomes que tiveram o respaldo da antiguidade" (Hume, 1994, p. 33). O segundo direito, o direito à propriedade, ainda que não tenha todo o peso que Harrington quis dar a ele quando pretendeu fundar todo governo na propriedade, é de grande importância, pois adiciona ao governante força e rendimentos, com os quais pode influenciar o corpo coletivo. A opinião é, então, segundo Hume, o que legitima a autoridade e consolida a obediência civil, e não o consentimento.

No ensaio "Da coalizão de partidos", Hume afirma que "abolir todas as distinções de partido pode não ser praticável, talvez nem desejável, em um governo livre" (Hume, 1994, p. 493). A divisão partidária pode garantir a harmonia entre autoridade e liberdade, que são os pilares de um bom governo. Em todos os governos, até mesmo nos absolutos, é fácil a propagação de divisões entre seus membros, principalmente porque "os homens têm tal propensão a se 
dividir em facções pessoais, que a mínima aparência de diferença real entre eles é suficiente para produzi-las" (Hume, 2008, p. 43). Essas divisões podem ser reais ou pessoais, esta é "fundada na amizade ou animosidade pessoal" e é mais comumente encontrada em "pequenas repúblicas", onde o poder é disputado por famílias de nobres; e aquela "em alguma diferença real de sentimento ou de interesse" (Hume, 2008, pp. 42-43). As divisões reais podem ser facções de interesse, de princípio e de afeto, embora estejam frequentemente misturadas de acordo com um ou outro tipo de governo. É mais fácil erradicar as divisões partidárias nas monarquias absolutas, pois a autoridade do rei tende a suprimir a liberdade dos membros do Estado, do que nas monarquias mistas, em que os partidos que "subvertem o governo, tornam as leis impotentes e geram as mais ferozes animosidades entre homens de uma mesma nação" (Hume, 2008, p. 42) são mais propriamente facções ou seitas.

$\mathrm{O}$ conflito que se estabeleceu na Inglaterra a partir das guerras civis opunha, por um lado, o partido Whig que, "ao fundar o governo inteiramente no consentimento do povo, supõe que exista um tipo de contrato original pelo qual os súditos reservaram tacitamente o poder de resistir ao seu soberano, sempre que se considerarem agredidos por essa autoridade, que confiaram a ele voluntariamente e para certos propósitos", e, por outro, o Tory que, "ao remontar o governo à Deidade, tenta torná-lo tão sagrado e inviolável, que seria um pouco menos que sacrilégio, por mais tirânico que seja, tocá-lo ou violá-lo ainda que minimamente" (Hume, 1994, p. 466). Depois da Revolução Gloriosa, principalmente durante o longo ministério de Robert Walpole, surgiu então outra denominação partidária, Corte e Campo, para designar, respectivamente, os apoiadores e opositores ao ministro. No entanto, nosso autor, nos ensaios que analisaremos sobre o contrato original e sobre a obediência passiva, endereça sua crítica ainda aos Whigs e aos Tories, justamente para se opor à ideia de que "a diferença real entre Whig e Tory se perdeu na revolução" (Hume, 1994, p. 71, grifo original).

Ainda que Tories e Whigs possam ser caracterizados como facções de "afeto", quando defendem diferentes famílias na sucessão do trono, ${ }^{6}$ sua disputa é mais caracterizada por princípios, cujas noções especulativas orientam a prática política de cada um dos partidos. Por essa razão, Hume se dedicará a analisar esses princípios "especulativos ou filosóficos" e suas "disputas históricas",

6 "Um Tory, portanto, desde a revolução, pode ser definido, em poucas palavras, como amante da monarquia, embora sem abandonar a liberdade, e partidário da família Stuart. Da mesma forma, um Whig pode ser definido como amante da liberdade sem, contudo, renunciar à monarquia, e um partidário do 'estabelecimento' (Settlement) da linhagem Protestante" (Hume, 1994, p. 71, grifos do original). 
apontando seus problemas e incoerências, e não raro a ausência de oposição entre suas ideias. Na posição de filósofo, nosso autor se recusa a defender um ou outro lado e, principalmente, diz que o fato de um filósofo abraçar um partido é "uma contradição em termos" (Hume, 1994, p. 469). Mais ainda, o intento de Hume é promover a moderação, mostrando que:

Ambos os sistemas de princípios especulativos são justos, embora não no sentido pretendido pelos partidos; e que ambos os esquemas de consequências práticas são prudentes, embora não a tal extremo com que cada partido, em oposição ao outro, esforça-se geralmente para conduzi-los (Hume, 1994, p. 466).

Hume retoma a argumentação dos Tories sobre a autoridade divina dos reis para refutá-la: uma vez que se admite, como queriam os membros desse partido, que a providência divina esteja na origem de "todos os eventos do universo", não se deve inferir que ela tenha dado origem a um "vice-gerente" na terra, pois "o melhor e mais legítimo príncipe" não teria, de acordo com essa ideia, mais razão "para alegar uma sacralidade ou autoridade inviolável peculiar do que um magistrado inferior, ou até mesmo um usurpador, ou até mesmo um ladrão ou um pirata" (Hume, 1994, p. 467). De outro modo, "as mesmas causas que deram origem ao poder soberano em cada estado estabeleceram também cada jurisdição e cada pequena autoridade. Um condestável, por conseguinte, age por indicação divina e possui um direito irrevogável tanto quanto um rei" (Hume, 1994, p. 467). Assim, se toda e qualquer autoridade tem origem divina, o princípio defendido pelos Tories não pode fundamentar exclusivamente a soberania dos reis.

Na análise dos princípios especulativos dos Whigs, Hume se concentrará na refutação da noção de contrato original. Ele argumenta, primeiramente, que, embora possamos conceber que na origem de algumas nações os membros de uma sociedade tenham fundado o governo sob a égide de um contrato, ele não é, de forma alguma, a fonte da soberania. Na verdade, os governos da atualidade não têm qualquer referência com esse consentimento original. A concepção de que os indivíduos, ainda hoje, "nascem iguais e não devem lealdade a qualquer príncipe ou governo, ao menos que comprometidos pela obrigação e sanção de uma promessa" (Hume, 1994, p. 469), é comum à teoria Whig, porém, em sua avaliação no ensaio "Do contrato original", Hume parece atribuí-la principalmente a Locke, conforme a doutrina apresentada no "Segundo Tratado do Governo". ${ }^{7}$ Este estabelece que os indivíduos, mesmo tendo nascido em uma

7 Como dissemos, Hume endereça sua crítica aos teóricos Whigs de maneira geral, mas em muitos momentos parece se referir ao "Segundo Tratado do Governo". No ensaio "Do Contrato Original", Hume indica 
sociedade civil já instituída, estão ligados voluntariamente ao corpo político, tendo como seu representante e juiz o poder legislativo. Assim, a obediência prestada ao governante tem como contrapartida a garantia dos fins para os quais a sociedade foi estabelecida. Para Hume, no entanto, esse raciocínio carece de exemplos da experiência:

Mas se esses pensadores olhassem para o mundo, não encontrariam nada que, no mínimo, corresponda a suas ideias ou possa justificar um sistema tão refinado e filosófico. Ao contrário, descobrimos em todo lugar príncipes que reivindicam seus súditos como sua propriedade e declaram seu direito independente de soberania por conquista e sucessão (Hume, 1994, pp. 469-470).

Igualmente, segundo Hume, não faltam evidências históricas, antigas e modernas, para ilustrar sua posição; na própria história da Inglaterra encontramos notícias da violência e autoridade dos reis a fim de consolidar seu governo. De acordo com o ensaio "Do contrato original",

Harry IV e Harry VII da Inglaterra realmente não tiveram outro título ao trono que a eleição parlamentar, ainda assim eles nunca reconheceriam isso, para que não enfraquecessem sua autoridade. É estranho, se considerarmos a única fundamentação da autoridade o consentimento e a promessa! (Hume, 1994, p. 473).

Em segundo lugar, a submissão aos governantes, sendo fruto de um contrato, pode, segundo os teóricos Whigs, admitir exceções; assim, "um excesso de tirania por parte dos governantes é suficiente para liberar os súditos de todo vínculo de obediência" (Hume, 2009, p. 589), garantido pelo direito de resistência. ${ }^{8}$ Para Hume, todavia, como a fonte dessa obrigação não é o contrato social, e sim sua utilidade para a sociedade, a resistência não pode ser uma prerrogativa dos súditos. É importante apontar que nosso autor admite a resistência - ao contrário dos Tories que rejeitam qualquer menção a ela -, pois, antes mesmo de qualquer teorização a esse respeito, precisamos reconhecer que a resistência é um fato, ou seja, a experiência mostra que em determinados momentos os súditos deixaram de obedecer ao poder instituído; no entanto, também não se pode determinar abstratamente quando a resistência é legítima, como queriam os Whigs. Na verdade, a única justificativa filosófica para a resistência estaria na ausência do "motivo original para a obediência", ou seja, "se é o interesse que gera primeiramente a obediência ao governo, a obrigação de obedecer tem de

explicitamente e cita trechos do "Tratado" de Locke. Conferir Hume (1994, pp. 486-487).

8 Também aqui Hume está pensando no direito de resistência tal como defendido por Locke. Outros teóricos Whigs, como Tyrrel, por exemplo, pensaram a resistência em termos diferentes dos de Locke. Sobre isso, vide Rudolph (2002). 
cessar toda vez que cessa o interesse em um grau significativo, e em um número considerável de casos" (Hume, 2009, p. 593). Ora, há vários exemplos em que essa máxima não foi observada, ainda que em algumas ocasiões a resistência pudesse ser justificada. Se os homens têm um sentido da enorme vantagem do governo para a ordem e a paz, não admitirão comumente "as convulsões que sempre acompanham as revoluções" (Hume, 2009, p. 593); por isso, somente em casos muito extremos, "quando a execução da justiça for seguida de consequências muito perniciosas" (Hume, 1994, p. 489), é que se deve dar lugar à exceção e "pôr em prática a doutrina da resistência" (Hume, 2009, p. 593). Nosso autor defende ainda que os teóricos que se dedicam a enumerar a priori as circunstâncias nas quais a resistência é justificável deveriam, ao contrário, concentrar-se na promoção da justiça e da obediência, que é a regra comum.

Outra consequência derivada da teoria do contrato social é a defesa de que a monarquia absoluta seja incompatível com a sociedade civil. Porque o estado de natureza em que os indivíduos se encontram em sua origem é "um estado de perfeita liberdade para ordenar-lhes as ações e regular-lhes as posses e as pessoas conforme acharem conveniente, dentro dos limites da lei de natureza, sem pedir permissão ou depender da vontade de qualquer outro homem" (Locke, 1983, p. 35), quando da instauração do governo, o homem de Locke só estará disposto a sacrificar toda sua liberdade mediante um contrato que garantirá um juiz mediador de controvérsias e reparador de danos; com efeito, esse contrato é firmado entre os membros de uma sociedade, que abdicam de seu "próprio poder executivo da lei de natureza" em prol do "bem público da sociedade" (Locke, 1983, p. 68). Se um tal juiz tem poderes absolutos, não será possível remediar os danos que porventura cause, o que caracteriza, portanto, uma volta ao estado de natureza:

Do que ficou dito é evidente que a monarquia absoluta, que alguns consideram o único governo do mundo, é, de fato, incompatível com a sociedade civil, não podendo por isso ser uma forma qualquer de governo civil, porque o objetivo da sociedade civil consiste em evitar e remediar os inconvenientes do estado de natureza que resultam necessariamente de poder cada homem ser juiz em seu próprio caso, estabelecendo-se uma autoridade conhecida para a qual todos os membros dessa sociedade podem apelar por qualquer dano que lhe causam ou controvérsia que possa surgir, e à qual todos os membros dessa sociedade terão de obedecer. Onde quer que existam pessoas que não tenham semelhante autoridade a que recorrerem para decisão de qualquer diferença entre elas, estarão tais pessoas no estado de natureza; e assim se encontra qualquer príncipe absoluto em relação aos que estão sob seu domínio (Locke, 1983, p. 68).

A exclusão das monarquias absolutas do quadro das sociedades civis é mais um ponto de disputa que Hume trava com os contratualistas. As sociedades livres continuam sendo melhores do que os governos absolutos, mas as monarquias 
civilizadas se desenvolveram muito nos tempos de Hume e não podem ser comparadas às tiranias antigas. Embora a história ofereça dados para pensarmos a política, é perigoso fazer excessivas generalizações a partir dos eventos históricos, pois há muitas diferenças entre as formas de governo antigas e modernas; se na antiguidade as artes e as ciências floresciam entre nações livres, o caso da França é exemplar para pensarmos a modernidade: este povo, afirma Hume, "levou as artes e as ciências tão próximas da perfeição quanto qualquer outra nação" (Hume, 2008, p. 64). Ademais, a monarquia foi a forma de governo que mais se desenvolveu com a civilização, sendo possível afirmar em relação a ela

o que antes só se dizia em louvor das repúblicas: são um governo de leis, não de homens. Elas se mostraram passíveis de um grau surpreendente de ordem, método e constância. Ali, a propriedade está assegurada, a indústria é encorajada, as artes florescem e o príncipe vive seguro entre seus súditos, como um pai entre filhos (Hume, 2008, p. 67).

Depois de debater as controvérsias filosóficas dos Whigs (e mais superficialmente dos Tories) nos ensaios "Do contrato original" e "Da obediência passiva", segundo o próprio Hume, outro exercício para a promoção da moderação dos partidos na Inglaterra, agora no ensaio "Da coalizão dos partidos", é a revisão de suas disputas históricas:

Exerceremos a seguir a mesma moderação com relação às disputas históricas entre os partidos, provando que cada um deles se baseava em tópicos plausíveis; que em ambos os lados havia homens sábios com boas intenções para com seu país; e que o fundamento da antiga animosidade entre as facções não passava de preconceito ou paixão interessada (Hume, 1994, p. 494, grifo original).

Ambos os partidos ingleses tentaram encontrar na história da Inglaterra princípios que justificassem suas posições; não por acaso, portanto, várias versões da história inglesa surgiram nos séculos XVII e XVIII, ${ }^{9}$ escritas tanto por partidários Whigs quanto Tories. Estes se apoiavam na história feudal do país para justificar o direito de sucessão e divino dos reis; aqueles tentavam buscar em um momento anterior, que remonta à invasão saxônica à ilha, a origem contratual do governo e do parlamento nas assembleias populares estabelecidas por esse povo. ${ }^{10} \mathrm{O}$ reconhecido "amor pela liberdade" (Hume, 2015, p. 17) dos

9 Podemos citar, a título de curiosidade, as obras de TYRREL, J. (1704). "The General History of England, Both Ecclesiastical and Civil; From the Earliest Accounts of Time, To the Reign of His Present Majesty, King William III". 3vols (London); CLARENDON, Earl of. (1702-1704). "The History of Rebellion and Civil Wars in England" (Oxford); e RAPIN, P. (1724-1727). "The History of England" (London).

10 Sobre a interpretação histórica Whig, Locke parece ter um papel controverso e minoritário. Sabemos que essa argumentação envolveu principalmente William Petyt e James Tyrrel, embora Hume não faça qualquer menção a esses autores. 
saxões, de acordo com o próprio Hume na "História da Inglaterra", dava ensejo aos Whigs para sustentar a tese de que nenhum outro princípio além da vontade popular poderia ter originado a constituição inglesa. Assim, os historiadores Whigs sugeriam que, se o contrato social deu origem ao governo inglês, as antigas liberdades estabelecidas pelos saxões foram usurpadas pelos Stuarts que, de forma tirânica, aumentaram as prerrogativas reais. Em contrapartida, os Tories afirmavam que, com a ausência de uma constituição livre anterior, todo o privilégio havia sido dado ao povo pela própria vontade do monarca, portanto a dissolução do parlamento por Carlos I não representara uma usurpação. De todo modo, o que nosso autor expõe no ensaio "Da coalizão dos partidos" como argumento Whig para a "recuperação da constituição antiga" (Hume, 1994, p. 497) é a necessidade de assegurar os privilégios do povo diante da crescente extensão das prerrogativas dos monarcas desde reinados até mesmo anteriores a Carlos I. A única forma de garantir o poder dos comuns seria, então, a retomada dos princípios da constituição anterior, que "apresenta exemplos de limitações mais restritas impostas à coroa” (Hume, 1994, p. 496).

Ainda que reconheça um aumento do poder dos reis que antecederam Carlos I, Hume considera ridícula essa interpretação Whig da história: não houve em qualquer momento da antiguidade maior liberdade do que se é possível gozar na atualidade, e na verdade, antes da Magna Carta o que havia era um controle dos barões sobre o rei, e não do povo sobre o rei. Mais ainda, os comuns têm um poder de governo sem precedentes, alicerçado principalmente no aumento de suas propriedades. A história inglesa demonstra, ao contrário dessas alegações, que "o presente governo monárquico" é,

em sua total extensão, autorizado por juristas, recomendado por teólogos, reconhecido por políticos, assentido, mais que isso, passionalmente querido, pelo povo em geral, e tudo isso durante um período de, pelo menos, cento e sessenta anos, e até recentemente, sem o menor murmúrio ou controvérsia (Hume, 1994, p. 499).

Uma vez que a teoria do contrato social organiza os princípios filosóficos e históricos dos Whigs é que Hume se dedicará a criticá-la. No entanto, em que medida essa crítica mais enfática aos Whigs não deve ser lida como um posicionamento em favor dos Tories? Ainda que Hume professe nos "Ensaios" seu interesse filosófico pela política sem partidarismos, a fim de promover a moderação de ambas as facções, em proveito da própria constituição inglesa, muitos estudiosos desconfiam dessa imparcialidade na "História da Inglaterra", 
principalmente por causa da sua retratação da dinastia Stuart, apoiada pelos Tories - Carlos I, por exemplo, é perfilado como digno, humano, corajoso e sóbrio (Hume, 1983, p. 354) - e de seu julgamento severo à execução do monarca. Em contrapartida, outros defendem a neutralidade da crítica de Hume, como Forbes (1975, p. 139), que contrasta o Whiggism vulgar dos partidários com o Whiggism científico ou cético do nosso autor: "não é o 'conservadorismo', mas o Whiggism cético envolvido na abordagem filosófica da política, que dá ao pensamento de Hume sua unidade e continuidade".

A despeito da querela em torno de sua imparcialidade, é preciso ressaltar o esforço de Hume para imprimir um caráter mais moderno à política, recusandose a tratar em primeiro plano do problema da soberania tão caro às facções: Hume pretende discutir os governos das nações tais como estabelecidos na sua atualidade. No que compete à história da Inglaterra, nos "Ensaios", muito mais do que tratar da origem do parlamento ou da autoridade do rei, Hume pretende discutir a relação delicada entre esses dois poderes e a necessidade de mantê-los em harmonia, a fim de se evitar tanto a licenciosidade quanto a tirania. Ademais, a divisão partidária ameaça a estabilidade política e social que são as bases para o desenvolvimento de uma nação; por isso, sua discussão visa ao estabelecimento de princípios que possam consolidar um governo de leis, não de homens. Uma constituição robusta garante que o bom funcionamento do governo não dependa do humor dos governantes e que a harmonia entre parlamento e monarca não dependa da habilidade pessoal do rei.

Exatamente porque é a opinião que dá legitimidade ao governo, garantindo a sua estabilidade, seja em uma monarquia absoluta ou em uma república, é que Hume, nos "Ensaios" mencionados, mas também na "História da Inglaterra", esforçou-se para influenciar positivamente a opinião dos homens em relação ao governo inglês. A política partidária não é considerada como um problema em si, mas, como nos informa Harris (2015, p. 340), "inevitável, dado o modo informal e mal definido sob o qual a constituição equilibrava autoridade e liberdade." Com efeito, Hume via como problemática somente a imoderação desses partidos, ou seja, a forma extremada com que defendiam seus princípios, nutrindo, consequentemente, "visões opostas com relação às essências do governo, à sucessão da coroa ou aos privilégios mais consideráveis pertencentes aos muitos membros da constituição" (Hume, 1994, p. 493).

"A condução do governo é apenas estável e previsível se seguir publicamente regras gerais conhecidas" (Haakonssen, 1993, p. 197), a despeito de seu sistema político. É por isso que, no ensaio "Que a política pode ser reduzida a uma ciência", nosso autor não defenderá nenhuma forma de governo específica, mas indicará, entre as formas existentes, a melhor maneira de organizá-las. 
Em diversos ensaios Hume discute a influência das diferentes formas de governo para o desenvolvimento das artes e ciência ("Do surgimento e progresso das artes e ciências" e "Da liberdade civil"), do comércio ("Da liberdade civil"), da densidade populacional ("Da densidade populacional das nações antigas"), entre outros, em uma clara indicação de que esses aspectos, além da liberdade civil, contribuem para a prosperidade de uma nação. Nesse sentido, a teoria política de Hume desenvolvida nos "Ensaios", em toda a sua complexidade, procurou debater temas caros à época, para muito além da motivação - e das opiniões - partidária que engajou muitos de seus contemporâneos.

\section{Referências}

FORBES, D. "Hume's Philosophical Politics". Cambridge: Cambridge University Press, 1975.

HAAKONSSEN, K. “The Structure of Hume's Political Theory”. In: D. Norton (ed.), 1993, pp. 182-221.

HARRIS, J. "Hume: an intellectual biography". New York: Cambridge University Press, 2015.

HUME, D. "Essays, Moral, Political and Literary". Indianapolis: Liberty Fund, 1994. . "AArte de Escrever Ensaio". Seleção Pedro Paulo Pimenta; tradução de Márcio Suzuki e Pedro Paulo Pimenta. São Paulo: Iluminuras, 2008.

. "Tratado da Natureza Humana". Tradução de Débora Danowski, 2a ed. São Paulo: Ed. UNESP, 2009.

"A Treatise of Human Nature". Edited by David Fate Norton and Mary J.

Norton. Oxford: Oxford University Press, 2000.

."The History of England, from the Invasion of Julius Caesar to the Revolution in 1688". 6 Vols. Indianapolis: Liberty Fund, 1983.

"História da Inglaterra: da Invasão de Júlio César à Revolução de 1688".

Seleção, tradução e apresentação de Pedro Paulo Pimenta. São Paulo: Ed. UNESP, 2015. LOCKE, J. "Segundo Tratado sobre o Governo". Traduções de Anoar Aiex e E. Jacy Monteiro, $3^{\text {a }}$ ed. São Paulo: Abril Cultural, 1983.

NORTON, D. (ed.). "The Cambridge Companion to Hume". Cambridge, United Kingdom: Cambridge University Press, 1993.

RUDOLPH, J. "A Revolution by Degrees, James Tyrrell and Whig Political Thought in the Late Seventeenth Century". New York: Palgrave, Macmillan, 2002. 